\title{
UTILIZATION OF THE HEALTH CARE DELIVERY SYSTEM IN A DISTRICT OF NORTH INDIA.
}

\author{
Nath Bhola ${ }^{1}$, Kumari $\mathrm{R}^{1}$, and Tanu Nidha ${ }^{2}$
}

Abstract

Background: India has one of the most extensive health infrastructures- a three-tier hierarchical referral system- for the provision of effective and efficient health services to the majority of its population. In this study we have tried to evaluate the utilization of such a wide health infrastructure and the various factors affecting it. We have also tried to find the factors that motivated the patients to visit the present health facility and the key persons who motivated them to do so.

Methods: Time bound cross-sectional study.

Setting: Three types of referral health facilities in Lucknow District

Participants: A total of 1265 patients were interviewed during the four months of the period of survey from these three types of referral health facilities.

Results: The present study revealed that majority of the patients coming to all the three referral centres were the new patients (89\%), about two-thirds of whom had come there directly. Overall, only one tenth of the patients attending the secondary and tertiary level public health facilities were referred by someone. Most of the indirect patients had self referred themselves. About eight and nine percent of the indirect and referred patients could reach the present site of treatment only after more than two years of rummaging and about $13 \%$ and $11 \%$ had spent more than ten thousand rupees respectively, which in some cases even amounted to lakh rupees. Conclusions: The utilization of the referral system of the health care delivery in India needs to be augmented. Before planning future reforms such as decentralization, incorporation of the Indian system of Medicine, and other steps we need to develop mechanisms to see that the plans are materialized.

Key Words: Utilization, Health care delivery System, Cost effectiveness, Referral System, India

\section{Introduction}

Health services in India rest traditionally upon a three-tier hierarchy of central, intermediate and peripheral levels $(1,2)$. With the aim of achieving an optimal level of health for its people, the Government of India launched the Rural Health Scheme in 1977 which is a three-tier system of health care delivery in rural areas based on the recommendations of the Srivastav Committee in 1975 (3). Apart from other areas of action, the committee recommended the development of a 'Referral Services Complex' by establishing proper linkages between the Primary Health Centre and higher level referral and service centres (4). The flow of health services in different countries is similar with some variations tailored according to the existing situation as is depicted in the Figure 1 (5). The results of the present study therefore can be applied in different situations based on the specific needs.

The objective of the present study was to evaluate the adequate utilization of such a wide and huge health infrastructure which may be influenced by its accessibility and the cost effectiveness of the services apart from various other factors. We have also tried to calculate the expenditure incurred and the duration spent by the indirect and the referred patients prior to the arrival at the present health facility. We have made an effort to postulate the reasons for the existing lacunae in the system and thus provide food for thought to the planners.

Correspondence to: Dr. Bhola Nath, 124A/186, Block No.11, Govind Nagar, Kanpur, Uttar Pradesh, 208006 - India, Telephone No. +91-9415161823

E-mail bholanath75@yahoo.co.in, jeeta21@sify.com, ${ }^{1}$ Department of Community Medicine, ${ }^{2}$ King George Medical University, Lucknow, India

Department of Community Medicine, G.S.V.M. Medical College, Kanpur

\section{Methodology}

\section{Study Design}

The present study was a cross sectional study conducted among the patients attending the government allopathic health facilities of Lucknow, a centrally placed district of Uttar Pradesh, a state in north India.

\section{Setting}

The sampling frame consisted of all the allopathic government health facilities of Lucknow district providing secondary and tertiary levels of health care. At the Tertiary level, it consisted of the King George Medical University and Sanjay Gandhi Post Graduate Institute with their associated hospitals. At the secondary level, Balrampur District Hospital, Civil hospital and eight Community Health Centres were included in the sampling frame.

\section{Period of study}

The data collection was carried out from April 2006 to July 2006.

\section{Sampling}

\section{Sample Size}

The number of patients interviewed was limited by the time frame of the survey. We could interview a total of 1265 patients during the four month survey period at the four health facilities.

\section{Sampling Technique}

At the tertiary level, Medical College (MC) was randomly selected while at the secondary level, Balrampur District hospital and two Community Health Centres (CHCs) were randomly selected. Further at the Medical College a total of 669 patients could be interviewed at the Out-Patient Departments (OPD) of 
Medicine, General Surgery, Obstetrics and Gynaecology, Paediatrics, Orthopaedics, Otorhinolaryngology, Ophthalmology, Cardiology, Neurology, Tuberculosis \& Chest diseases. At the District hospital (DH), 395 patients attending the OPD's of Medicine, General surgery, Obstetrics \& Gynaecology and Paediatrics were interviewed while 201 patients were interviewed from the two randomly selected CHCs.

\section{Selection of the participants}

The selection of the patients was through systematic random sampling, depending upon the previous years OPD attendance and the time taken to complete the interview.

\section{Inclusion Criteria:}

A "new" or "referred" patient attending the OPD of the respective health care facility was included in the study. A "new" patient was any patient attending the present health facility for the first time for the present episode of illness. The new patients were again divided into two groups of "direct" and "indirect" patients. The "direct" patients were those who had not consulted anywhere else and had come directly to the present health facility for the present episode of illness, while the "indirect" patients had consulted at other health facilities prior to the visit to the present health facility. These "indirect" patients had either self referred themselves or had been motivated by someone. They were not provided with a written referral note even if they were motivated by a doctor. The "referred" patients included those referred to the present health care facility with a referral note by a health professional.

\section{Exclusion Criteria}

Patients working in the health care facility, Follow up patients attending the OPD of the respective health care facility, Tools of data collection:

Permission to conduct the study was obtained from the respective health care facilities. Informed verbal consent was taken before starting the interview from each patient after explaining him/her the objectives of the study. To ensure comparability of the data collected, the interview was taken by the same person at each of the health facility. A quantitative structured interview schedule was used to record information pertaining to the sociodemographic characteristics of the patient, the motivating factors that brought them to the health facility, the reasons for coming to the present health facility after having consulted somewhere else, the duration of treatment at the other health facility and the expenditure in terms of direct costs incurred in the process. We also asked the patients about the person who motivated him/her to visit the present health facility as well as the qualification of the doctor who referred the patient.

\section{Analysis}

Data were tabulated on Microsoft Excel sheet and analyzed using the software 'Epi Info version 6 and Microsoft Excel (Analysis toolpak) for Windows XP.

\section{Results}

It was observed that the majority of the patients were in the economically productive age group. The distribution regarding the locality of the patients was in accordance with the distribution of the population in the district, with around $70 \%$ coming from an urban locality. As expected the proportion of the urban patients was more in the $\mathrm{MC}$ and the $\mathrm{DH}$ while that at the CHC mostly consisted of the rural population. It was observed that most of the patients coming to the public health facilities were the new patients, about two-thirds of which had come directly. Only one tenth of the patients attending the secondary and tertiary level public health facilities were referred by a health professional (Not shown in the table).

Faith on the doctors and health facility (81\%), availability of the specialists (54.5\%), the proximity of the health facility (29\%) and cost effectiveness of the treatment provided (24.8\%) were cited as the major reasons for direct visit to the health facility (Table 1 ).

Inability to derive any substantial benefit from the treatment provided at the other health facilities was the most common reason (87.1\%) for the visit to the present health facility in the indirect patients. About $17 \%$ and $13 \%$ of the patients cited cost effectiveness of the public health facilities and the availability of a specialist respectively as a reason for the change in the place of consultation (Table 2).

While some significant differences were observed in the duration spent to reach the present health facility between the indirect patients and the referred patients at the various health facilities, the differences were not found to be significant on the whole except for those who took six to twelve months to reach the present health facility. Unfortunately, eight and nine percent of the indirect and the referred patients respectively could reach the present site of treatment only after more than two years of rummaging (Table 3 ).

Evaluation of the direct costs involved in obtaining the treatment prior to arrival at the present health facility revealed that about three out of five patients had spent more than 1000 Rupees before visiting the present health facility in both the groups, with about $13 \%$ and $11 \%$ of the indirect and the referred patients respectively spending more than ten thousand rupees, which in some cases even amounted to lakh rupees (Table 4). We observed no statistically significant differences with respect to the expenditure in the two groups of the patients.

Most of the indirect patients (76.2\%) had self referred themselves, while others were motivated by the doctors or the staff of some health care facility. People who had received satisfactory treatment from the MC also motivated others to seek treatment from there (Table 5).

Majority of the patients were referred by a specialist (68.3\%) or a MBBS doctor (15.8\%). The referrals made by the practitioners of other system of medicine to the allopathic health facilities was not very encouraging (12.3\%) (Table 6). 
Table 1. Motivating factors for the direct visit of the patients to the public health facilities of Lucknow district

\begin{tabular}{|c|c|c|c|c|c|c|c|c|}
\hline & \multicolumn{2}{|c|}{ Tertiary } & \multicolumn{4}{|c|}{ Secondary } & \multirow[b]{3}{*}{ No. } & \multirow[b]{3}{*}{$\%$} \\
\hline & \multicolumn{2}{|c|}{$\operatorname{MC}^{a}(321)$} & \multicolumn{2}{|c|}{$\mathrm{DH}^{b}(\mathbf{3 0 1})$} & \multicolumn{2}{|c|}{$\mathrm{CHC}^{\mathrm{C}}(\mathbf{1 7 2})$} & & \\
\hline & No. & $\begin{array}{l}\text { Factors } \\
\text { for }\end{array}$ & $\begin{array}{l}\text { Level of } \\
\text { health }\end{array}$ & $\begin{array}{l}\text { Total } \\
(\mathbf{7 9 4})\end{array}$ & No. & $\%$ & & \\
\hline Cost effectiveness & 27 & 8.4 & 120 & 39.9 & 50 & 29.1 & 197 & 24.8 \\
\hline Faith on doctors and health facility & 243 & 75.7 & 267 & 88.7 & 133 & 77.3 & 643 & 81.0 \\
\hline Facilities for investigations present & 5 & 1.6 & 5 & 1.7 & 2 & 1.2 & 12 & 1.5 \\
\hline $\begin{array}{l}\text { Someone known works in the health } \\
\text { facility }\end{array}$ & 29 & 9.0 & 6 & 2.0 & 2 & 1.2 & 37 & 4.7 \\
\hline Specialists available & 189 & 58.9 & 229 & 76.1 & 15 & 8.7 & 433 & 54.5 \\
\hline Near to residence & 34 & 10.6 & 63 & 20.9 & 133 & 77.3 & 230 & 29.0 \\
\hline Someone known lives in Lucknow & 5 & 1.6 & 5 & 1.7 & 0 & 0 & 10 & 1.3 \\
\hline
\end{tabular}

Table 2. Reasons for consulting the public health facility in the indirect patients ${ }^{a}$

\begin{tabular}{|c|c|c|c|c|c|c|c|c|}
\hline \multirow{4}{*}{ Reasons } & \multicolumn{6}{|c|}{ Level of health care } & & \\
\hline & \multicolumn{2}{|c|}{ Tertiary } & \multicolumn{4}{|c|}{ Secondary } & \multicolumn{2}{|c|}{ Total(332) } \\
\hline & \multicolumn{2}{|c|}{$\mathrm{MC}^{b}(229)$} & \multicolumn{2}{|c|}{$\mathrm{DH}^{c}(\mathbf{7 5})$} & \multicolumn{2}{|c|}{$\mathrm{CHC}^{d}(\mathbf{2 8})$} & \multirow[b]{2}{*}{ No. } & \multirow[b]{2}{*}{$\%$} \\
\hline & No. & $\%$ & No. & $\%$ & No. & $\%$ & & \\
\hline No benefit & 205 & 89.5 & 62 & 82.7 & 22 & 78.6 & 289 & 87.1 \\
\hline Cost effectiveness & 24 & 10.5 & 26 & 34.7 & 6 & 21.4 & 56 & 16.9 \\
\hline Specialists available & 36 & 15.7 & 4 & 5.3 & 2 & 7.1 & 42 & 12.6 \\
\hline Someone known lives in Lucknow & 13 & 5.7 & 4 & 5.3 & 0 & 0 & 17 & 5.1 \\
\hline $\begin{array}{l}\text { Someone known works in the health } \\
\text { facility }\end{array}$ & 13 & 5.7 & 0 & 0 & 0 & 0 & 13 & 3.9 \\
\hline Other & 31 & 13.5 & 9 & 12.0 & 3 & 10.7 & 43 & 12.9 \\
\hline
\end{tabular}


Table 3. Duration of treatment in the indirect and referred patients prior to the visit to the present health facility.

\begin{tabular}{|c|c|c|c|c|c|}
\hline \multirow{2}{*}{ Types of patients } & \multicolumn{5}{|c|}{ Duration of treatment } \\
\hline & $<1$ months & 1-6 months & 6-12 months & $1-2$ years & $>2$ years \\
\hline $\begin{array}{l}\text { Medical college } \\
\text { Indirect patients } 229\end{array}$ & $102(44.5)$ & $75(32.7)$ & $19(8.2)$ & $10(4.4)$ & $23(10.0)$ \\
\hline Referred 119 & 59 (49.6) & 39 (32.8) & $3(2.5)$ & $6(5.0)$ & $12(10.1)$ \\
\hline $\begin{array}{l}\chi^{2} \text { value } \\
\text { P value }\end{array}$ & $\begin{array}{c}19.43 \\
0.00\end{array}$ & $\begin{array}{l}0.00 \\
0.99\end{array}$ & $\begin{array}{l}4.40 \\
0.03\end{array}$ & $\begin{array}{l}0.08 \\
0.77\end{array}$ & $\begin{array}{l}0.00 \\
0.99\end{array}$ \\
\hline District Hospital & & & & & \\
\hline Indirect patients 75 & $40(53.3)$ & $24(32.0)$ & $7(9.3)$ & $1(1.3)$ & $3(4.0)$ \\
\hline $\begin{array}{l}\text { Referred } 19 \\
\chi^{2} \text { test } \\
\text { P value }\end{array}$ & $\begin{array}{c}17(89.5) \\
8.21 \\
0.00\end{array}$ & $\begin{array}{c}1(5.3) \\
5.49 \\
0.01\end{array}$ & $\begin{array}{l}0(0) \\
0.80 \\
0.37\end{array}$ & $\begin{array}{l}0(0) \\
0.56 \\
0.45\end{array}$ & $\begin{array}{c}1(5.3) \\
0.15 \\
0.69\end{array}$ \\
\hline Community Health Centre & & & & & \\
\hline Indirect patients 28 & $21(75.0)$ & $3(10.7)$ & $2(7.1)$ & $1(3.6)$ & $1(3.6)$ \\
\hline Referred 1 & $1(100)$ & $0(0)$ & $0(0)$ & $0(0)$ & $0(0)$ \\
\hline $\begin{array}{l}\chi^{2} \text { test } \\
\text { P value }\end{array}$ & $\begin{array}{l}0.38 \\
0.53\end{array}$ & $\begin{array}{l}1.76 \\
0.18\end{array}$ & $\begin{array}{l}3.00 \\
0.08\end{array}$ & $\begin{array}{l}6.74 \\
0.00\end{array}$ & $\begin{array}{l}6.74 \\
0.00\end{array}$ \\
\hline $\begin{array}{l}\text { Total indirect patients } \\
332\end{array}$ & $\begin{array}{c}163 \\
(49.1)\end{array}$ & $\begin{array}{c}102 \\
(30.7)\end{array}$ & $\begin{array}{c}28 \\
(8.4)\end{array}$ & $\begin{array}{c}12 \\
(3.6)\end{array}$ & $\begin{array}{c}27 \\
(8.1)\end{array}$ \\
\hline Total referred patients 139 & 77 (55.4) & 40 (28.8) & $3(2.1)$ & $6(4.3)$ & $13(9.4)$ \\
\hline $\begin{array}{l}\chi^{2} \text { test } \\
\text { P value }\end{array}$ & $\begin{array}{l}1.55 \\
0.21\end{array}$ & $\begin{array}{l}0.18 \\
0.67\end{array}$ & $\begin{array}{l}6.26 \\
0.01\end{array}$ & $\begin{array}{l}0.13 \\
0.71\end{array}$ & $\begin{array}{l}0.19 \\
0.66\end{array}$ \\
\hline
\end{tabular}

Number in Parentheses indicate percentages $P$ value less than 0.05 is considered significant

Table 4. Direct cost of treatment in the indirect and referred patients prior to the visit to the present health facility.

\begin{tabular}{|c|c|c|c|c|}
\hline \multirow[b]{2}{*}{ Types of patients } & \multicolumn{4}{|c|}{ Money spent (INR) in the treatment prior to coming to the present health facility } \\
\hline & $<1000$ & $1000-5000$ & $5000-10000$ & $\geq 10000$ \\
\hline \multicolumn{5}{|l|}{ Medical College } \\
\hline Indirect patients 229 & 93 (40.6) & 72 (31.4) & $23(10.0)$ & $41(17.9)$ \\
\hline Referred 119 & 47 (39.5) & 38 (31.9) & $19(16.0)$ & $15(12.6)$ \\
\hline $\begin{array}{l}\chi^{2} \text { test } \\
\text { P value }\end{array}$ & $\begin{array}{l}0.04 \\
0.84\end{array}$ & $\begin{array}{l}0.01 \\
0.92\end{array}$ & $\begin{array}{l}2.58 \\
0.10\end{array}$ & $\begin{array}{l}1.62 \\
0.20\end{array}$ \\
\hline \multicolumn{5}{|l|}{ District Hospital } \\
\hline Indirect patients 75 & $40(53.3)$ & $26(34.7)$ & $6(8.0)$ & $3(4.0)$ \\
\hline Referred 19 & $13(68.4)$ & $5(26.3)$ & $0(0)$ & $1(5.3)$ \\
\hline$\chi^{2}$ test & 1.39 & 0.47 & 1.61 & 0.06 \\
\hline$\tilde{P}$ value & 0.23 & 0.49 & 0.20 & 0.80 \\
\hline \multicolumn{5}{|l|}{ Community Health Centre } \\
\hline Indirect patients 28 & $20(71.4)$ & $4(14.2)$ & $3(10.7)$ & $1(3.6)$ \\
\hline Referred 1 & $1(100)$ & $0(0)$ & $0(0)$ & $0(0)$ \\
\hline$\chi^{2}$ test & 0.38 & 0.16 & 1.76 & 6.74 \\
\hline P value & 0.53 & 0.68 & 0.18 & 0.00 \\
\hline Total indirect patients 332 & $153(46.1)$ & $102(30.7)$ & $32(9.6)$ & $45(13.6)$ \\
\hline Total referred patients 139 & $61(43.9)$ & $43(30.9)$ & $19(13.7)$ & $16(11.5)$ \\
\hline$\chi^{2}$ test & 0.19 & 0.00 & 1.64 & 0.36 \\
\hline$P$ value & 0.66 & 0.96 & 0.19 & 0.54 \\
\hline
\end{tabular}

Number in Parentheses indicate percentages, $\quad \mathrm{P}$ value less than 0.05 is considered significant 
Table 5. Distribution of the indirect patients according to the persons who motivated them to visit the present health facility

\begin{tabular}{|c|c|c|c|c|c|c|c|c|}
\hline \multirow{3}{*}{$\begin{array}{l}\text { Person who motivated to consult the } \\
\text { concerned health facility }\end{array}$} & $\begin{array}{l}\text { Leve } \\
\text { terti }\end{array}$ & ealth & Secc & ary & & & Tota & \\
\hline & \multicolumn{2}{|c|}{$\mathrm{MC}_{\mathrm{b}}(229$} & \multicolumn{2}{|c|}{$\mathrm{DH}_{\mathrm{c}}(\mathbf{7 5 )}$} & \multicolumn{2}{|c|}{ CGC (28) } & \multirow[b]{2}{*}{ No. } & \multirow[b]{2}{*}{$\%$} \\
\hline & No. & $\%$ & No. & $\%$ & No. & $\%$ & & \\
\hline Self & 174 & 76.0 & 57 & 76.6 & 22 & 78.6 & 253 & 76.2 \\
\hline Government Doctor & 23 & 10.0 & 26 & 34.6 & 6 & 21.4 & 55 & 16.5 \\
\hline Neighbour & 12 & 5.2 & 4 & 5.3 & 0 & 0 & 16 & 4.8 \\
\hline $\begin{array}{l}\text { Person who had a already visited this } \\
\text { facility and got relieved }\end{array}$ & 13 & 5.7 & 0 & 0 & 0 & 0 & 13 & 3.9 \\
\hline Others & 26 & 11.4 & 9 & 12.0 & 3 & 10.7 & 38 & 11.4 \\
\hline
\end{tabular}

a- Includes multiple responses, ${ }^{b}$ - Medical College, ${ }^{c}$ - District Hospital, ${ }^{d}$ - Community Health Centre

Table 6. Distribution of the patients according to the qualification of the doctor who referred them to the present health facility.

\begin{tabular}{|c|c|c|c|c|c|c|c|c|}
\hline \multirow[b]{4}{*}{ Qualification } & \multirow{2}{*}{\multicolumn{6}{|c|}{ Level of health care }} & \multirow{3}{*}{\multicolumn{2}{|c|}{ Total (139) }} \\
\hline & & & & & & & & \\
\hline & \multicolumn{2}{|c|}{$\begin{array}{c}\text { Tertiary } \\
M^{a}(119)\end{array}$} & \multicolumn{3}{|c|}{ Secondary } & $\mathrm{CHC}^{c}$ (1) & & \\
\hline & No. & $\%$ & No. & $\%$ & No. & $\%$ & No. & $\%$ \\
\hline Quack & 3 & 2.5 & 2 & 10.5 & 0 & 0 & 5 & 3.6 \\
\hline Unani & 5 & 4.2 & 3 & 15.8 & 0 & 0 & 8 & 5.8 \\
\hline Ayurvedic & 2 & 2.5 & 4 & 21.1 & 0 & 0 & 6 & 4.3 \\
\hline Homeopathy & 3 & 1.7 & 0 & 0 & 0 & 0 & 3 & 2.2 \\
\hline M.B.B.S. & 16 & 13.4 & 5 & 26.3 & 1 & 100 & 22 & 15.8 \\
\hline Specialist and above & 90 & 75.6 & 5 & 26.3 & 0 & 0 & 95 & 68.3 \\
\hline
\end{tabular}

Figure 1: The flow of care between the four different levels of health care in different countries

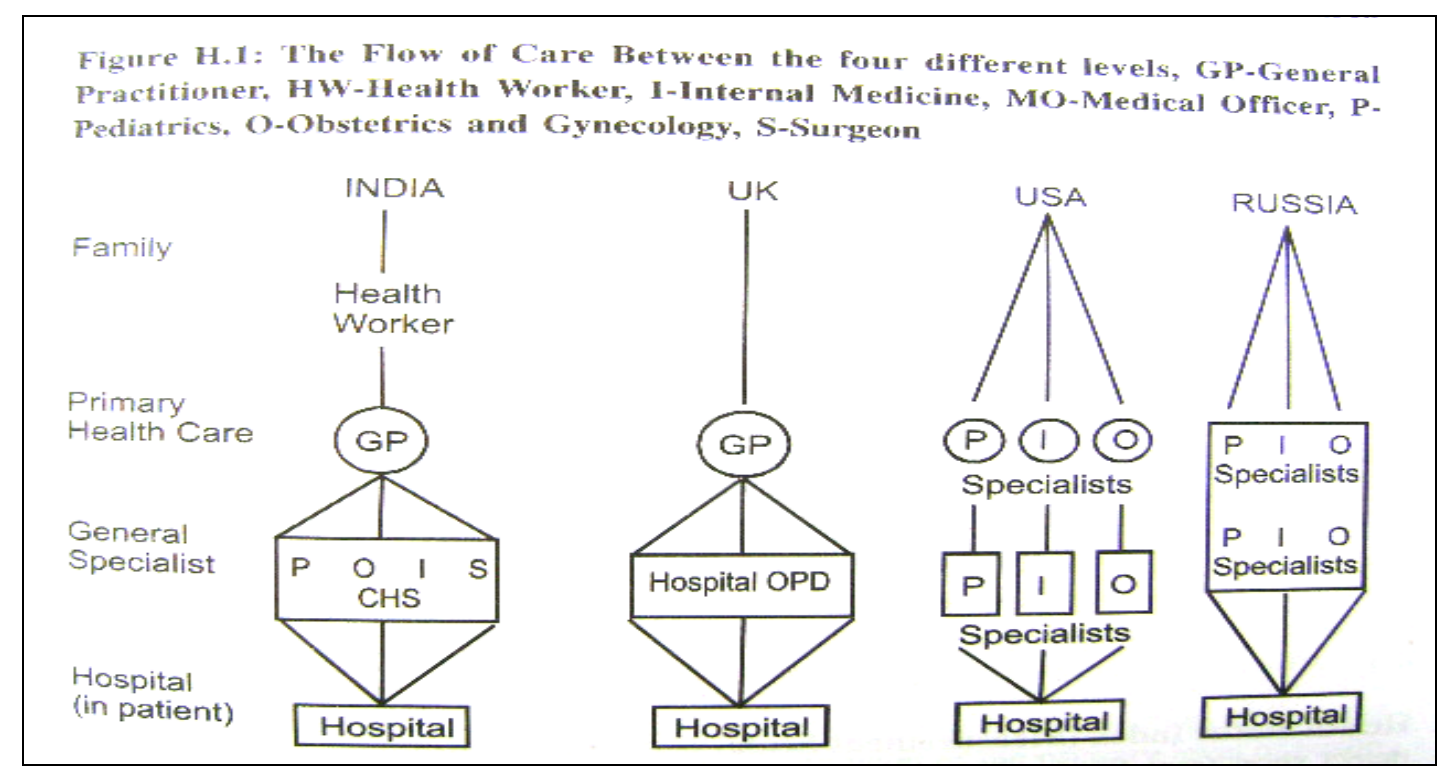




\section{Discussion:}

The present study was an attempt to study the utilization of the existing health care delivery system in a district of North India. Since the health care delivery system in different countries is similar with some differences, the findings of the study will be helpful while we try to make certain reforms in the health care delivery system of the country, especially the developing ones, to increase the effectiveness and efficiency of the system.

We observed that majority of the patients coming to all the three "referral" centers, particularly the CHCs were the new patients. Strikingly, only one out of 201 patients was referred to the "first referral centre" of the health care delivery system in India i.e. the CHC, indicating a grave underutilization of the system. This is especially important in the light of the fact that, the health system of India is composed of different health centers and hospitals which act as a hierarchy of referral centers to deliver different levels of health care $(1,2)$.

The correspondingly low proportion of referred patients and a high percentage of the direct patients to the MC coerces us to give a thought to the health care delivery system in the urban areas which has largely been neglected and hence been deprived of the government institutions for the primary level of health care. The planners have always portrayed India as a rural country and developed plans accordingly. The recent improvements envisaged in the National Rural Health Mission (NRHM) have also been focused mainly on the rural areas (6). The rapid urbanization and the mushrooming of the slums in the urban areas, and the consequent needs of the people have largely been ignored (7). The private sector flourishing in the urban areas is not within the reach of the common man and the accessibility to the various health insurance schemes and other agencies such as Railways and Defence services is also limited $(8,9)$. This is bound to put the pressure on the specialized health services. We therefore have to plan a similar system of health care delivery in the urban areas as is running in the rural areas with simultaneous plans to ensure its utilization.

The awareness of the general population regarding their health and their effort to consult the best available doctor and health facility for restoration of their optimal health is a good sign, but is not without other undesirable consequences. It imposes overburden on the specialized health facilities as revealed by another study also in another developing country (10). Unfortunately this burden is more due to the common ailments rather than cases requiring specialized care. Gate keeping arrangements by defining the catchments area of the health facilities and taking measures for ensuring channelisation of the patients through the various levels of health care system as was conceptualized at the beginning might be a helpful solution. This has been successfully experimented in Kharar Hospital in Punjab (11).

Cost effectiveness of the health care was one of the important reasons responsible for the direct and indirect visit to the health facilities. Analysis of the data from the 1999 Health Sector Beneficiary Assessment in Mozambique, another developing country, suggested that physical access, education, and economic variables remain important determinants in decisions about outpatient visits (12). This finding becomes more important when majority of the patients (about 70\%) in our study belonged to the lower socioeconomic status, thus emphasizing the monetary constraint that they would face while spending on the process of consultation with the doctor which would include the direct costs incurred on the transportation, registration, investigations and the treatment and the indirect cost in terms of loss of wages due to the absenteeism from the work (13). On the other hand, not citing cost effectiveness as the "most" important reason for the visit emphasizes that factors such as faith and satisfaction are more important for a patient who is ready to pay for receiving the specialized care despite the financial limitations.

A perplexing finding of the study was the proximity of the health facility being the major reason for the direct visit to the CHC. People were treating the $\mathrm{CHC}$ as a Primary health centre (PHC) and visiting it for treatment of common ailments, because of the non availability of a PHC in the near vicinity as stated by $77 \%$ of the people. This compels us to question the location of the various PHCs and the definition of their catchment area. If the accessibility of a CHC is better than a PHC, it is destined to draw more patients than the PHC which will hence be underutilized. Therefore the accessibility of the health facility as a major factor in the utilization of the health service which has also been highlighted in the principles of Primary health care cannot be overemphasized and the practical aspects need to be reviewed (14).

About $87 \%$ of the indirect patients had resorted to a change in place of the consultation because of their inability to derive any benefit from the treatment provided at the other health facilities. Further, since they were not referred to the present health facility by a health professional, their certainty of arrival at the appropriate place of treatment was still questionable and may well add to the plight of their situation as revealed by another study also (15).

The delay in the arrival of the indirect as well as referred patients at the MC was significant in the light of the fact that the best course of management for most of the diseases is early diagnosis and treatment for the prevention of complications which are mostly irreversible. The effect of a delay in treatment is further compounded by the expenditure on the health care during this period especially when it is not accompanied by any satisfactory benefit. Late referral also limits therapeutic options, and these limitations have consequences on long-term outcomes. The consequences of late referral in terms of increased morbidity, mortality, and resource utilization, as well as adverse impact on patients' quality of life and missed opportunities for pre-emptive treatment have been emphasized by Levin A (16) and Alebiosu CO (17) in their study. 
With a per capita income of Rs. 22,379 annually (18) expenditure (in terms of direct costs) of more than 1000 Rupees before visiting the present health facility in about three out of five patients is quite high. The indirect costs involved were not evaluated and could well add to the gravity of the situation. Especially surprising was the finding that a substantial number of the patients were referred to the health facility after they had spent more than ten thousand rupees, indicating a delay in the decision to refer. Specific guidelines regarding the referral of the patients would be helpful in making timely referral, thus economizing on both time and money and more importantly the health of the patient. The presence of majority of the patients in the economically productive groups adds to the indirect cost of the treatment. Another major group of the patients were the children who were usually accompanied by some elder person mostly the mother or the father, which implies that they must have taken a days off from the regular duties further adding to the indirect cost of the consultation. The dependant status of about three-fourths of the total patients is also a significant finding in terms of the economic burden subjected to the bread earner of the family.

The referral through the Indian system of medicines (ISM) such as Ayurvedic, Homeopathic or Unani system was not found to be very heartening. The integration of the ISM in the health system of the country as is envisaged in the National Rural Health Mission, still waits to be materialized (19). With the widespread quackery in the country $(20,21)$, it was not surprising to see people being consulted by quacks, but it was unusual to see them participating in the referral system and sending the patients for better treatment at the specialized health facilities. This is a good sign and we can think of mainstreaming them in the health system of the country with some training as has been successfully experimented with the village health guides and the local dais.

We therefore come to the conclusion that the utilization of the referral system of the health care delivery in India still needs to be enhanced and before planning future reforms such as decentralization, incorporation of the Indian system of Medicine, infrastructural corrections and other steps we need to develop mechanisms to see that the plans are materialized. Regular and independent evaluation would help us to assess the achievement of the stated objectives and the reasons for non achievement. The present study might serve as an eye opener and oblige us to think beyond the horizon, to question the establishment of such a huge infrastructure and its appropriate utilization.

\section{Limitations:}

The present study was a time bound study and therefore lacks an appropriate sample size calculation. Although the information about the number of referred patients could well be obtained by a primary data but the secondary data provided by the present study would help in supplementing the information along with educing the reasons for the existing situation. We also lacked data for comparison due to the relative lack of other similar studies, which was another limitation for our study. A prospective study on the patients referred to the higher centers would provide us with a clearer picture about the compliance with and defect in the referral system.

\section{References:}

1. Rural Health Care System in India. (Available at http://mohfw.nic.in/dofw\%20website/Bulletin\%20on\%20RHS\%20-\%2006\%20$\% 20$ PDF\%20Files/Genesis\%20and\%20Evolution\%20of\%20RHCSModified.htm, Accessed April, 2008)

2. Organizational Structure Available at httpnagahealth.nic.invision \%20of\%20Deptt.htm, Accessed April, 2008)

3. Park K. Health Care of the community. Park's Text Book of Preventive and Social Medicine. $18^{\text {th }}$ Edition. Jabalpur: Banarsidas Bhanot Publishers; 2005: 695.

4. Park K. Health Planning and Management. Park's Text Book of Preventive and Social Medicine. 18 $^{\text {th }}$ Edition. Jabalpur: Banarsidas Bhanot Publishers; 2005: 672 .

5. Kishore. J Medical Dictionary of Public health. $2^{\text {nd }}$ Edition. New Delhi: Century Publication; 2002: 402-403

6. National Rural Health Mission (2005-2012). Ministry of Health and Family Welfare, Government of India. (Available at http://mohfw.nic.in/NRHM/Task grp/Mission Document.pdf, Accessed April, 2008

7. Srinivasa C, Urban Health Care in India. (Available at http://www.ananthapuri.com/article.asp?title=Urban-Health-Care-inIndia\&id=44, Accessed April, 2008)

8. Ministry of Health \& Family Welfare, Report of the National Commission on Macroeconomics and Health, Government of India, New Delhi, August 2005: 5

9. Bagchi D, Towards Accessibility of Health Services by the Poor in India through Micro Health Insurance Scheme: An Exploratory Study. (Available at http://www.rmi.nccu.edu.tw/apria/docs/Concurrent\%20V/Session \%201/3607he alth_insurance_apria_2007.doc, Accessed April, 2008)

10. Atkinson S, Ngwengwe A, Macwan'gi M, Ngulube TJ, Harpham T, O'Connell A. The referral process and urban health care in sub-Saharan Africa: the case of Lusaka, Zambia.

11. Soc Sci Med 1999 Jul; 49(1):27-38.

12. Organization of the referral system, Kharar Hospital, Punjab (Available at http://www.cbhi-hsprod.nic.in/listdetails.asp?roid=223, Accessed April, 2008 ).

13. Lindelow $M$. Understanding spatial variation in the utilization of health services: does quality matter? CSAE \& the World Bank. (Available at http://www.bepress.com/cgi/viewcontent.cgi?article $=1212 \&$ context $=$ csae, Accessed April, 2008)

14. Department of Health and Human Services, Report on Disease-specific estimates of direct and indirect costs of illness and NIH support, National Institutes of Health, Bethesda, U.S.A., February 2000.

15. WHO (1978). Alma Ata 1978: Primary Health Care, HFA Sr. No. 1.

16. Ravinder P.S. Makkar, Monga A, Arora A, Mukhopadhyay S, Gupta AK. Selfreferral to specialists - a dodgy proposition. Int J Health Care Qual Assur 2003; 16(2): 87 - 89.

17. Levin A. Consequences of late referral on patient outcomes. Nephrol Dial Transplant 2000; 15(3):8-13.

18. Alebiosu CO. Detrimental effects of late referral for dialysis. Afr J Health Sci 2001 Jan-Jun; 8(1-2):89-92.

19. Government of India, Revised estimates of Annual National Income, 2006-07 and Quarterly estimates of Gross Domestic Product, 2006-07, Press Information Bureau, May 2007. (Available at http://mospi.nic.in/pressnote 31mav07.htm, Accessed April, 2008)

20. Kishore J. National Rural Health Mission (2005-2012). National Health Programmes of India. 6th Edition. New Delhi: Century Publication; 2006: 3641.

21. After kidney scam, India looking at anti-quackery bill, Indian E news, Sunday 3 Feb 2008. (Available at http://www.indiaenews.com/health/20080203/95322.htm)

22. Umre AG. Quackery - A Burning Threat of Human Health. J Indian Med Assoc 2007 Aug; 105(8):423. 